\title{
FUNGSI TRAFFIC ACCIDENT RESEARCH CENTRE UNTUK MENDUKUNG PROGRAM KESELAMATAN BERLALULINTAS
}

\author{
Traffic Accident Research Centre Functions to Support the Traffic Safety Program
}

\author{
Muhammad Tito Karnavian \\ Kepolisian Negara Republik Indonesia \\ Jl. Trunojoyo No.3, Jakarta Selatan, DKI Jakarta \\ mabes@polri.go.id
}

\begin{abstract}
Road safety is the crisis condition in developing countries such as Indonesia. Based on 2016 data, the death tolls of road accidents were 26,000, or 10.9 fatalities per 100,000 inhabitants. The majority of victims were between 15 and 29 years old (IRSMS, 2016). This condition shows the human capital losses caused by many die prematurely on the road. The Long Term National Road Safety Plan (RUNK) declared in 2011 has the main goal is reducing road fatalities by $50 \%$ and $80 \%$ in 2020 and 2035, respectively. Indonesia National Police (INP) has the main role in coordinating and realizing safer road users in the RUNK. Integrated Road Safety Management System (IRSMS) is the road accident data-based application that was developed by INP, and it must be evidence-based for decision policies and development action plan activities. Establishment of Traffic Accident Research Centre (TARC) has the main objective of synergizing Indonesia traffic police with academia and researcher to carry out in-depth study as well as to develop programs that able both structural and cultural to construct safety concern society. INP understands that the enforcement program solely cannot solve road safety problems. It recognizes that achievement is not possible without understanding the problems and incorporation with all stakeholders in road safety.
\end{abstract}

Key Words: Road Safety; Traffic Accident Databased; Traffic Accident Research Centre.

\begin{abstract}
Abstrak
Keselamatan di jalan raya adalah sesuatu hal yang kritis di negara berkembang seperti Indonesia. Data kecelakaan pada tahun 2016 menunjukan 26.000 orang, 41.9 orang per 100.000 penduduk meninggal di jalan raya dimana mayoritas korban berusian 15 - 29 (IRSMS, 2016). Kondisi memperlihatkan kehilangan negara atas aset sumber daya yang dimiliki. Rencana Umum Nasional Keselamatan (RUNK) pada tahun 2011 bertujuan menurunkan fatalitas di jalan raya. POLRI mempunyai peran utama dalam mengkoordinasi dan menciptakan pengguna jalan yang berkeselamatan. Integrated Road Safety Management System (IRSMS) adalah aplikasi pencatatan data kecelakaan yang dikembangkan oleh POLRI harus dijadikan basis pengambilan keputusan dan aktifitas kampanye keselamatan di jalan raya. Pendirian Traffic Accident Research Centre (TARC) bertujuan menciptakan sinergitas antara KORLANTAS POLRI dan akademisi dalam melakukan in-depth study serta. Penciptaan program yang mampu secara struktur dan kultur menciptakan masyarakat yang berperilaku pengutamaan terhadap keselamat karena melakukan tindakan represif semata-mata tidak dapat menyelesaikan masalah keselamatan jalan.
\end{abstract}

Kata Kunci: Keselamatan jalan raya; Integrated Road Safety Management; Traffic Accident Research Centre.

\section{PENDAHULUAN}

Setiap tahun diperkirakan 1,24 juta orang meninggal dunia di jalan, serta terdapat 20 - 50 juta orang yang mengalami luka ringan akibat kecelakaan lalu lintas (WHO, 2015). Di 
Indonesia 26.000 orang atau dengan kata lain 41,9 per 100.000 penduduk meninggal di jalan raya pada tahun 2015 (IRSMS, 2016). Kejadian kecelakaan dan kematian tersebut memiliki dampak yang sangat besar terhadap keluarga yang bersangkutan karena kehidupan mereka akan berubah dan tidak bisa kembali lagi seperti dahulu akibat kejadian tersebut, dan juga berdampak pada lingkungan tempat orang-orang tersebut tinggal dan bekerja.

Kecelakaan lalu lintas diperkirakan akan menjadi penyebab kematian global kedelapan, dengan dampak serupa yang disebabkan oleh penyakit menular seperti malaria. Kecelakaan lalu lintas juga menjadi penyebab kematian paling tinggi untuk kelompok usia 15-29 tahun, dan hal itu membawa kerugian besar bagi mereka yang sedang memasuki usia produktif. Indonesia menghadapi permasalahanyang sama dengan jumlah korban fatalitas akibat kecelakaan lalu lintas saat ini sekitar 28.000 jiwa dan diperkirakan kerugian ekonomi sebesar 2\% hingga 3\% dari Gross National Product.

Peningkatan keselamatan jalan secara global telah dikaitkan dengan visi pembangunan berkelanjutan dan menjadi prioritas dalam menangani pengurangan kemiskinan, serta pencapaian Sustainable Development Goals (SDGs). Hal ini sejalan dengan konsep pembangunan bangsa yang telah memasukkan unsur pendidikan dan kesehatan, yang sebelumnya hanya berfokus pada pendapatan dan pengeluaran ${ }^{1}$. Jumlah kerugian terhadap kesehatan akibat kecelakaan lalu lintas menjadikan keselamatan lalu lintas menjadi prioritas pembangunan di negara-negara dengan penghasilan menengah ke bawah. Hal yang menjadi perhatian khusus adalah bahwa kematian dan cedera akibat kecelakaan lalu lintas menjadi kemelut yang berkembang untuk kelompok usia muda, terutama pria. Jelas bahwa fatalitas kecelakaan akan mengganggu pencapaian sasaran Indeks Pembangunan Manusia (IPM) Indonesia.

Untuk menghadapi permasalahan di atas, pemerintah telah membuat arah kebijakan keselamatan jalan di Indonesia dituangkan dalam Rencana Umum Nasional Keselamatan (RUNK) Jalan yang dideklarasikan oleh pemeintah pada tahun 2011. RUNK bertujuan untuk mengurangi tingkat kematian per jumlah penduduk sebesar 50\% pada tahun 2020, dan $80 \%$ pada tahun 2035, dengan menggunakan tingkat kematian pada tahun 2010 sebagai dasar perhitungan (RUNK, 2011).

Pada tahun 2013, Instruksi Presiden (Inpres) No.4/2013 dan telah menetapkan programprogram khusus untuk Dekade Aksi Keselamatan Jalan tahun 2011-2020 (bercermin pada program-program di RUNK untuk 10 tahun pertama) yang didukung oleh instansi-instansi terkait dengan rencana kegiatan tahunan untuk setiap aksi.

Menindaklanjuti amanat Undang Undang Nomor 22 Tahun 2009I telah membuat Rencana Utama Nasional Keselamatan Jalan 2011 - 2035 (RUNK) pada tahun 2011. RUNK mengacu pada Rencana Global Dekade Aksi PBB Tahun 2011 - 2020 dan lima (5) pilar sistem keselamatan jalan. Lima pilar tersebut adalah manajemen keselamatan jalan, jalan yang berkeselamatan, kendaraan yang berkeselamatan, pengguna jalan yang berkeselamatan, dan respon sebelum-sesudah terjadinya kecelakaan.

\footnotetext{
${ }^{1}$ Kritik terhadap kesuksesan ekonomi negara yang hanya memperhatikan indikator Gross National Product (GNP) per kapita sudah banyak dituangkan dalam berbagai literature karena hanya memperhatikan ukuran ekonomi saja untuk memperlihatkan hasil pembangunan. Pada tahun 1990, UNDP memperkenalkan indeks baru yang mencerminkan pembangunan berkelanjutan dengan memasukan komponen kesehatan dan Pendidikan (lihat pada UNDP, 1995 dan publikasi tahun-tahun berikutnya).
} 
RUNK didasari oleh prinsip-prinsip keberlanjutan, kegiatan-kegiatan yang terkoordinasi dan kooperatif untuk meningkatkan keselamatan jalan, yang mencerminkan suatu pemahaman bahwa kondisi keselamatan jalan hanya dapat ditingkatkan melalui kerjasama seluruh masyarakat Indonesia. Rencana Aksi tersebut belum resmi disahkan oleh Pemerintah Indonesia pada tahun 2011, tapi hal tersebut terus memberikan panduan yang berguna untuk menyusun program-program jangka pendek dan jangka menengah untuk para pemangku kepentingan. Pada akhirnya tahun 2013, Instruksi Presiden No.4/2013 ditetapkan oleh Presiden Republik Indonesia dan menetapkan kegiatan-kegiatan khusus dengan instansi-instansi terkait dan pembuatan rencana kegiatan tahunan dengan koordinator masing-masing pilar adalah Kementerian Perencanaan Pembangunan Nasional/Bappenas, Kementerian Pekerjaan Umum dan Perumahan Rakyat, Kementerian Perhubungan, Kepolisian Negara Republik Indonesia (POLRI), dan Kementerian Kesehatan (Sekretaris Kabinet Republik Indonesia, 2013).

Di sini jelas bahwa POLRI mempunyai peran utama dalam mengkoordinasikan dan menciptakan pengguna jalan yang berkeselamatan. Walaupun demikian POLRI juga mempunyai tugas-tugas di empat pilar lainnya. Di dalam arahan dari Decade of Action for Road Safety 2011-2020 yang dipublikasikan oleh Badan Kesehatan Dunia yang juga menjadi acuan RUNK/Inpres No 4 tahun 2013 membutuhkan riset-riset keselamatan jalan agar rencana-rencana aksi keselamatan jalan memiliki dasar yang tepat untuk berkontribusi dalam upaya pengurangan korban fatalitas baik jangka pendek maupun jangka panjang. Hal ini semakin mendesak mengingat target dari dekade aksi keselamatan jalan 2011-2020 diperkirakan tidak akan tercapai sehingga apa yang dilakukan saat ini atau business-asusual tidak dapat dipertahankan lagi pada tahun-tahun ke depan. Satu-satunya cara, yaitu dengan menggunakan data yang valid dan terpercaya sebagai fakta permasalahan dan upaya-upaya rencana aksi yang lebih efektif berdasarkan suatu kajian ataupun upaya-upaya terbaik (best practice) yang pernah dilakukan baik dari dalam maupun luar negeri. Hingga saat ini POLRI belum memiliki unit untuk melakukan riset tersebut, untuk itu Kepala Kepolisian Republik Indonesia menugaskan Korps Lalu Lintas (Korlantas) POLRI untuk membentuk suatu unit penelitian yang dikhususkan untuk kajian keselamatan jalan.

\section{SISTEM PENCATAN KECELAKAAN LALULINTAS DI INDONESIA}

Program-program keselamatan jalan harus direncanakan berdasarkan fakta permasalahan yang ada sehingga mampu diukur efektifitasnya. Untuk ini Polri telah memperbaiki sistem pencatatan data kecelakaan lalu lintas dari sistem manual ke sistem Integrated Road Safety Management System (IRSMS) berbasis web yang diberlakukan secara nasional sejak tahun 2013. IRSMS dirancang untuk dapat menyediakan data kecelakaan yang valid, terpercaya, dan kuat. Informasi mengenai situasi kejadian kecelakaan menjadi dasar untuk semua intervensi terkait sasaran keselamatan jalan. Misalnya, akses terhadap data kecelakaan lalu lintas yang komprehensif, terpercaya, dan akurat dapat membantu mengidentifikasi spesifikasi jalan, kendaraan, dan pengguna jalan, sehingga dapat diketahui hal-hal mana yang memerlukan intervensi keselamatan jalan. IRSMS merupakan kontribusi terbesar Polri di dalam mendukung Manajemen Keselamatan Jalan yang handal dan terpercaya (Yahya et al., 2013).

Saat menganalisis informasi kecelakaan, dengan menggunakan fasilitas peta, konsentrasi kecelakaan dapat dilihat dengan memperbesar lokasi tertentu. Para pengguna setiap saat dapat membuka sebuah data kecelakaan dan akan mendapatkan rangkuman deskripsi 
mengenai waktu, lokasi, kendaraan yang terlibat, dan jenis cedera. Diagram kecelakaan dan gambar pada saat kecelakaan juga dapat ditampilkan. Sejumlah laporan standar seperti laporan harian, mingguan, dan bulanan serta tabel standar juga tersedia untuk para pengguna. Sistem juga dapat melakukan tabulasi silang dari setiap variabel yang ada dalam sistem tersebut. Gambar 1 memperlihatan contoh dari tampilan peta IRSMS.

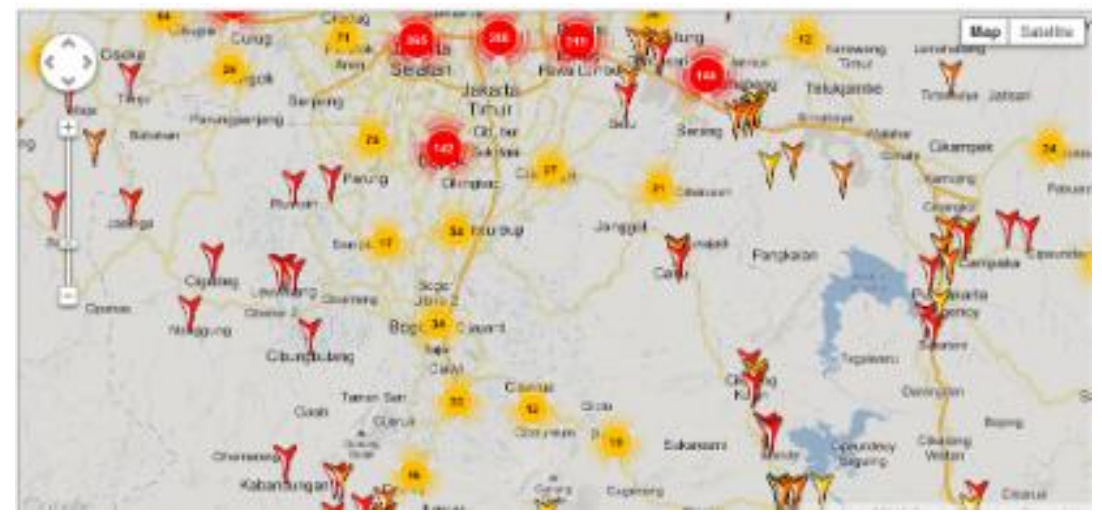

Gambar 1. Contoh tampilan IRSMS

Berdasarkan pengalaman-pengalaman yang sudah teruji, sebuah 'mesin' pemerintah yang koheren dengan fokus yang sangat jelas pada hasil-hasil yang diinginkan selalu terbukti berhasil, dimana instansi-instansi yang terlibat dalam mengemban tanggung jawab sungguh-sunggu bekerja sama di bawah koordinasi instansi utama untuk mencapai sasaransasaran keselamatan jalan. Saat ini IRSMS sudah mampu memberikan informasi kepada semua pemangku kepentingan untuk mengukur hasil dari berbagai rencana aksi yang diprogramkan.

IRSMS dapat dijadikan landasan untuk melaksanakan strategi-strategi keselamatan jalan di Indonesia, yaitu:

1. Mengaplikasikan sistem yang berkeselamatan.

2. Melakukan koordinasi ke tingkat pemerintah daerah, karena diperlukan RUNK untuk tingkat provinsi, kota, dan kabupaten.

3. Menyepakati program-program penegakan hukum.

4. Program-program kemitraan antara antara para pemangku kepentingan ataupun dengan dunia usaha melalui corporate social responsibility (CSR) ataupun filantropis.

5. Mengembangkan proyek percontohan yang komprehensif dan peningkatan kapasitas agar dapat mengikuti perkembangan teknologi termutakhir.

6. Memantau dan mengevaluasi pelaksanaan program.

Untuk mampu meningkatkan pencapaian, perlu didukung oleh riset-riset di semua pilar agar rencana-rencana aksi dapat disusun dan disesuaikan dengan kondisi struktur dan kultur Indonesia maupun kearifan berdasarkan budaya-budaya nusantara.

\section{TRAFFIC ACCIDENT RESEARCH CENTRE (TARC) POLRI}

TARC POLRI yang didirikan tahun 2018 merupakan suatu unit yang melaksanakan program penelitian keselamatan jalan yang terdiri dari kolaborasi antara akademisi dan Kepolisian Lalu Lintas (KORLANTAS POLRI). Tujuan utama dari unit ini yaitu, untuk melakukan penelitian ilmiah dalam keselamatan jalan selain itu juga agar polisi tidak 
gagap dengan perubahan zaman pada semua kebijakan yang dibentuk dengan reasearch dari terciptanya knowlage transfer dari peneliti ke praktisi untuk langsung di aplikasikan.

Undang-Undang Nomor 22 Tahun 2009 ini melihat bahwa lalu lintas dan angkutan jalan mempunyai peran strategis dalam mendukung pembangunan dan integrasi nasional sebagai bagian dari upaya memajukan kesejahteraan umum. Selanjutnya didalam batang tubuh dijelaskan bahwa tujuan yang hendak dicapai oleh Undang-Undang ini adalah:

1. Terwujudnya pelayanan Lalu Lintas dan Angkutan Jalan yang aman, selamat, tertib, lancar dan terpadu dengan moda angkutan lain untuk mendorong perekonomian nasional, memajukan kesejahteraan umum, memperkukuh persatuan dan kesatuan bangsa, serta mampu menjunjung tinggi martabat bangsa;

2. Terwujudnya etika berlalu lintas dan budaya bangsa; dan

3. Terwujudnya penegakan hukum dan kepastian hukum bagi masyarakat.

Kecelakaan dapat terjadi karena berbagai faktor, penyebab yang paling banyak adalah akibat kecerobohan pengendara itu sendiri. Misalnya, mengoperasikan handphone pada saat berkendara, tidak mematuhi rambu-rambu lalulintas dan lain-lain. Banyak kasus-kasus pelanggaran yang dilakukan pengendara sepeda motor, yang dapat membahayakan diri mereka sendiri, antara lain:

1. Pengendara sepeda motor senantiasa akan mencari jalan atau celah agar tidak terhalang kendaraan didepannya, baik dengan cara menyalip kendaraan didepannya atau bahkan sampai naik ke trotoar sehingga para pejalan kaki menjadi ketakutan.

2. Mematikan atau tidak memfungsikan dengan sengaja lampu motor, baik lampu utama, lampu rem ataupun lampu "sign", sehingga hal ini akan sangat membahayakan dirinya sendiri dan kendaraan lain dibelakangnya.

3. Mengubah bentuk kendaraan yang dapat merugikan orang lain, misalnya menghilangkan sparkboard belakang, sehingga ketika hujan dapat membuat cipratan banyak ke kendaraan lain. Dan masih banyak lagi pelanggaran-pelanggaran lain.

Dalam kaitan ini kepengurusan dalam dewan peneliti terdiri dari berbagai dosen dari berbagai perguruan tinggi di Indonesia, Perguruan/Sekolah Tinggi Ilmu Kepolisian dan Korlantas. Aktivitas awal dari TARC adalah sebagai berikut:

1. Menerbitkan Jurnal "Journal of Indonesia Road Safety"

2. Memberikan insentif penelitian keselamatan jalan

3. Publikasi-publikasi kajian keselamatan jalan yang dilakukan Korlantas

4. Membantu melakukan evaluasi kegiatan-kegiatan Korlantas

5. Melakukan program pelatihan keselamatan jalan

6. Mengikuti konferensi internasional dan penyelenggarakan simposiun keselamatan jalan

Jurnal ini direncanakan diterbitkan 3 kali dalam satu tahun dan dalam dua tahun harus mendapatkan akreditasi dari pemerintah dan merupakan jurnal on-line sehingga dapat dengan mudah diakses oleh masyarakat. Bila memungkinkan juga memiliki versi berbahasa Inggris yang dapat dijadikan referensi bagi para peneliti keselamatan jalan dunia berkaitan. Selain itu bantuan dana penelitian akan diupayakan diberikan kepada peneliti yang bersama dengan polisi untuk melakukan penelitian berdasarkan tematik yang dihadapi oleh Indonesia, maupun secara global. Terdapat 7 (tujuh) hal yang dikonsentrasikan Korlantas Polri berdasarakan data-data pelanggaran dan kecelakaan lalulintas, yaitu: 
1. Penggunaan helm yang masih rendah di Indonesia bagi pengguna sepeda-motor,

2. Penggunaan sabuk pengaman (seat-belt) baik kendaraan pribadi maupun angkutan umum,

3. Mengemudi dalam pengaruh minuman keras maupun obat,

4. Keselamatan anak-anak dalam berlalu-lintas di jalan. Khusus untuk ini WHO hanya menekankan pada child restraint pada saat di dalam kendaraan, tetapi khusus untuk Indonesia termasuk upaya-upaya agar anak di bawah usia mengendarai kendaraan, khususnya sepeda motor.

5. Mengendarai kendaraan berlawanan arus, khususna bagi pengguna sepeda motor'

6. Penggunaan telepon genggam (handphone) saat mengendarai kendaraan, dan

7. Pelanggaran batas kecepatan maksimal (speeding)

Keterlibatan polisi bersama dengan akademia/peneliti sangat penting agar terjadi proses pembelajaran dan memahami permasalahan yang ada ataupun sebaliknya. Diharapkan TARC mampu melakukan penelitian-penelitian yang mendesak yang diperlukan oleh Korlantas dan para pemangku kepentingan lainnya untuk mempunyai rencana aksi yang secara efektif dapat menurunkan kecelakaan lalu lintas dan fatalitas korban. Demikian pula TARC harus mampu membantu Korlantas di dalam mengevaluasi program-program rencana aksi keselamatan jalan dan operasi-operasi Kepolisian di bidang Lalu Lintas agar dapat diukur keberhasilannya maupun diketahui permasalahan yang dihadapinya. Penggunaan "big data" dan aplikasi "internet-of-think" juga harus dilakukan. Demikian penelitian untuk masalah adaptasi teknologi seperti Intelligent Transportation System (ITS).

Di dalam TARC harus mampu menghimpun pakar-pakar keselamatan jalan dan transportasi yang didukung pakar-pakar lainnya antara lain di bidang pendidikan, psikologi, sosiologi, teknologi informasi, hukum dan ilmu kepolisian.

Hasil produk harus mampu menjawab permasalahan keselamatan jalan dan menciptakan program yang mampu secara struktur dan kultur masyarakat yang berperilaku mengutamakan keselamatan, karena melakukan tindakan represif semata-mata tidak dapat menyelesaikan masalah keselamatan jalan.

\section{PENUTUP}

Polri dalam mewujudkan Postur yang profesional, modern dan terpercaya (Promoter) sangat membutuhkan suatu unit riset, khususnya di bidang lalu lintas jalan. Diharapkan dengan keberadaan unit riset di Korlantas Polri, upaya Polri untuk mewujudkan keselamatan jalan dalam rangka terciptanya keamanan, ketertiban, keselamatan dan kelancaran lalu lintas akan sangat terbantu dan lebih optimal dalam pelaksanaannya.

\section{DAFTAR PUSTAKA}

RUNK (2011) National Road Safety Master Plan (Rencana Umum Nasional Keselamatan) 2011-2035. Jakarta: BAPPENAS.

Sekretaris Kabinet Republik Indonesia (2013) Intruksi Presiden RI Nomor 4 tentang Program Aksi Keselamatan Jalan. Indonesia.

Sekretaris Negara Republik Indonesia (2009) 'Undang Undang Nomor 22 Tahun 2009 Tentang Lalu Lintas dan Angkutan Jalan'. 
WHO (2015) Global Road Safety Report. Geneva.

United Nations Development Programme (1995) Human Development Report. Oxford University Press, New York.

Yahya, M. N. et al. (2013) Development of an Integrated Road Safety Management System in Indonesia: Traffic Police as Lead Agents in a Safe System Approach, Journal of the Australian College of Road Safety, 24(2). 